\title{
Region-Specific Involvement of BDNF Secretion and Synthesis in Conditioned Taste Aversion Memory Formation
}

\author{
Ling Ma, ${ }^{1}$ Dong-Dong Wang, ${ }^{1}$ Tian-Yi Zhang, ${ }^{1}$ Hui Yu, ${ }^{1}$ Yue Wang, ${ }^{1}$ Shu-Hong Huang, ${ }^{1}$ Francis S. Lee, ${ }^{2}$ \\ and Zhe-Yu Chen ${ }^{1}$ \\ 'Department of Neurobiology, Shandong Provincial Key Laboratory of Mental Disorders, School of Medicine, Shandong University, Jinan, Shandong \\ 250012, Peoples Republic of China, and 2Department of Psychiatry, Weill Cornell Medical College of Cornell University, New York, New York 10065
}

Brain-derived neurotrophic factor (BDNF) and its receptor, tropomyosin-related kinase receptor B (TrkB), play a critical role in activitydependent plasticity processes such as long-term potentiation, learning, and memory. It has been shown that BDNF exerts different or even opposite effects on behavior depending on the neural circuit. However, the detailed role of BDNF in memory process on the basis of its location has not been fully understood. Here, we aim to investigate the regional specific involvement of BDNF/TrkB in hippocampalindependent conditioned taste aversion (CTA) memory processes. We found region-specific changes in BDNF expression during CTA learning. CTA conditioning induced increased BDNF levels in the central nuclei of amygdala (CeA) and insular cortex, but not in the basolateral amygdala (BLA) and ventromedial prefrontal cortex. Interestingly, we found that the enhanced TrkB phosphorylation occurred at the time point before the increased BDNF expression, suggesting rapid induction of activity-dependent BDNF secretion by CTA learning. Moreover, targeted infusion of BDNF antibodies or BDNF antisense oligonucleotides revealed that activity-dependent BDNF secretion and synthesis in the CeA, but not the BLA, was respectively involved in the short- and long-term memory formation of CTA. Finally, we found that infusion of exogenous BDNF into the CeA could enhance CTA learning. These data suggest that region-specific BDNF release and synthesis temporally regulate different CTA memory phases through activation of TrkB receptors.

\section{Introduction}

Brain-derived neurotrophic factor (BDNF), a molecule known to regulate neuronal survival and differentiation, plays a critical role in synaptic plasticity, long-term potentiation, learning, and memory (Barde et al., 1987; Leibrock et al., 1989; Huang and Reichardt, 2001; Chao, 2003). Increasing evidence indicates that inhibition of BDNF signaling via the tropomyosin-related kinase receptor $\mathrm{B}$ (TrkB) in the hippocampus or amygdala leads to impaired memory acquisition, retention, and/or recall in the water maze, fear-potentiated startle, and passive avoidance tests (Linnarsson et al., 1997; Minichiello et al., 1999; Mu et al., 1999; Alonso et al., 2002; Rattiner et al., 2004). Despite the importance of BDNF/TrkB signaling in learning and memory, most studies are currently focused on the hippocampal- or amygdaladependent memory processes, while reports focusing on the role of BDNF/TrkB in hippocampal-independent cortical learning are limited. Moreover, there is indeed considerable evidence showing that BDNF exerts different or even opposite effects on

Received 0ct. 12, 2010; revised Nov. 24, 2010; accepted Dec. 2, 2010.

This study was supported by the National Natural Science Foundation of China (Grants 30725020,31071254, and 31070991), the National 973 Basic Research Program of China (Grants 2010CB912004 and 2009CB941403), Science and Technology Development Projects of Shandong Province (Grant 2008GG30002039), State Program of National Natural Science Foundation of China for Innovative Research Group (Grant 81021001), and the Foundation for Excellent Young Scientists of Shandong Province (Grant BS2009SW028).

Correspondence should be addressed to Zhe-Yu Chen, Department of Neurobiology, School of Medicine, Shandong University, No. 44 Wenhua Xi Road, Jinan, Shandong 250012, Peoples Republic of China. E-mail: zheyuchen@sdu.edu.cn.

DOI:10.1523/JNEUROSCI.5348-10.2011

Copyright $\odot 2011$ the authors $\quad 0270-6474 / 11 / 312079-12 \$ 15.00 / 0$ depression-like behaviors depending on the neural circuit (Eisch et al., 2003; Krystal and Duman, 2004; Berton and Nestler, 2006; Berton et al., 2006). However, the detailed role of BDNF in memory processes on the basis of its regional location has not been fully understood.

Studies have demonstrated that blocking BDNF function by delivering BDNF antisense oligonucleotide (ASO) or BDNF antibodies into hippocampus could impair long-term memory (LTM) in contextual fear conditioning or inhibitory avoidance tests (Alonso et al., 2002; Lee et al., 2004). However, there are conflicting reports about whether BDNF is involved in shortterm memory (STM) formation (Alonso et al., 2002; Lee et al., 2004). Recently, the human BDNF Val66Met polymorphism, which leads to decreased activity-dependent BDNF secretion, was found to be associated with hippocampal-dependent episodic STM deficit (Egan et al., 2003; Chen et al., 2004, 2006). Together, it remains of interest to investigate the contribution of BDNF and its activity-dependent secretion in distinct memory process.

Conditioned taste aversion (CTA) is a form of learning where the subject associates a novel taste [termed the conditioned stimulus (CS)] with a subsequent transient visceral illness [termed the unconditioned stimulus (US)], and is an established model for studying the molecular mechanisms of nondeclarative memory in different brain regions. CTA is formed by single-trial training and is a long-lasting memory that provides a useful model for studying the different phases of memory, such as acquisition, consolidation, and retrieval. On the basis of the typical CTA paradigm, the brain regions involved in CTA formation should be 
those where taste and general visceral information associate such as the insular cortex (IC), the amygdala, the parabrachial nucleus (PBN), and the nucleus of the solitary tract (Gallo et al., 1998; Berman et al., 2000). In addition, recent studies have reported that ventromedial prefrontal cortex (vmPFC) plays an important role in CTA memory (Mickley et al., 2005; Yu et al., 2009). In the present study, the regional specific involvement of BDNF secretion and synthesis in the CTA memory process is investigated.

\section{Materials and Methods}

Animals. Wistar rats (2-month-old males, 250-300 g) were caged individually at $22^{\circ} \mathrm{C}$ under $12 \mathrm{~h} \mathrm{light/dark} \mathrm{cycles.} \mathrm{Water} \mathrm{and} \mathrm{food} \mathrm{were} \mathrm{avail-}$ able ad libitum except when experimental requirements dictated otherwise. All procedures were in accordance with the National Institutes of Health Guide for the Care and Use of Laboratory Animals and were approved by the institutional animal care and use committee of Shandong University.

Behavioral procedures. The behavioral protocol of CTA was performed according to previously published protocols (Desmedt et al., 2003). For the CTA study, saccharin $(0.1 \% \mathrm{w} / \mathrm{v}$, sodium salt) was used as an unfamiliar taste (CS), and intraperitoneal injection of $\mathrm{LiCl}(0.15 \mathrm{M}, 2 \%$ body weight) was the unconditioned stimulation (US). In brief, rats were deprived of water for $24 \mathrm{~h}$ and then given two pipettes containing $10 \mathrm{ml}$ of water each for $10 \mathrm{~min}$ once a day. They were trained 3-4 $\mathrm{d}$ to get their daily water ration. On conditioning day, the rats were presented with two pipettes containing $5 \mathrm{ml}$ of saccharin each for 10 min. Forty minutes later, they were injected with $\mathrm{LiCl}$ intraperitoneally. Four hours after conditioning, the rats were presented with a random array of six pipettes, three containing $3 \mathrm{ml}$ of saccharin and three containing $3 \mathrm{ml}$ of water for $10 \mathrm{~min}$. The rats explored to consume or avoid the contents of the pipettes, and their liquid consumption was recorded to test CTA STM. On the next $2 \mathrm{~d}$, rats were presented daily for $10 \mathrm{~min}$ with two pipettes containing $10 \mathrm{ml}$ of water each. On the third day after conditioning, rats were presented with an array of six pipettes, three containing $5 \mathrm{ml}$ of saccharin and three containing $5 \mathrm{ml}$ of water, to test CTA LTM. Conditioned rats preferred a water/saccharin ratio of 9:1 on their STM and LTM tests in this multiple-choice situation, whereas unconditioned rats preferred saccharin to water. For the weak CTA conditioning, all rats were trained as above, except that on the conditioning day, rats received intraperitoneal injection of $0.05 \mathrm{M} \mathrm{LiCl}$ ( $2 \%$ body weight) instead of 0.15 $\mathrm{M} \mathrm{LiCl}$. The results were quantified by an aversion index (AI), defined as $\mathrm{AI}=[($ milliliters of water $) /($ milliliters of water + milliliters of saccharin) $] \times 100 \%$ consumed in the test.

Quantitative real-time reverse transcriptase-PCR. After CTA conditioning, rats in the experimental group were killed at different time points after CS-US pairing ( $n=5$ per time point). Different from the CS-US paired group (CTA group), on the conditioning day the CS-alone group was given saccharin without $\mathrm{LiCl}$ injection before being killed, while the US-alone group received only an injection of $\mathrm{LiCl}$. In addition, in accordance with a previous study showing that there was an absence of learning an aversion when the abdominal irritation ( $\mathrm{LiCl}$ injection) was manipulated $24 \mathrm{~h}$ after taste (Gutiérrez et al., 2003), in the CS-US long (CS-US-L) group rats received $\mathrm{LiCl}$ injection $24 \mathrm{~h}$ after receiving saccharin. Last, a control group $(n \geq 5)$ that underwent habituation was killed from their home cages in the animal housing facility. For the rats infused with BDNF antibodies or BDNF oligonucleotides (ODNs), at least five animals from each group were killed at $4 \mathrm{~h}$ after CTA conditioning.

Brains were removed after decapitation, and then coronal sections ( 1 $\mathrm{mm}$ thick) were obtained using a rat brain slicer (Braintree Scientific). Five different brain regions from each rat [vmPFC, IC, basolateral amygdala (BLA), central nuclei of amygdala (CeA), and hippocampus] were punched according to the atlas (Paxinos and Watson, 1996) using a blunt-end 17 gauge syringe needle ( $1 \mathrm{~mm}$ inner diameter) and frozen in liquid nitrogen followed by RNA extraction. Total RNA was isolated using TRNzol-A ${ }^{+}$RNA isolation reagent (catalog \#DP421-02, TIANGEN) according to the manufacturer's instructions. A $0.5 \mu \mathrm{g}$ aliquot of each sample was treated with DNase to avoid DNA contamination, and then was reversely transcribed using the RevertAid First Strand
cDNA Synthesis Kit (catalog \#K1621, Fermentas). Primer sequences used were as follows: BDNF forward primer: $5^{\prime}$ TAA ATG AAG TTT ATA CAG TAC AGT GGT TCT ACA 3', and reverse primer: 5' AGT TGT GCG CAA ATG ACT GTT T 3' (Alfonso et al., 2006); nerve growth factor (NGF) forward primer: 5' GCT CAT CCA CCC ACC CAG TCT TCC 3', and reverse primer: 5' CTC GCC CAG CAC TGT CAC CTC CTT 3'; and neurotrophin-4/5 (NT4/5) forward primer: 5' GAG GCA CTG GCT CTC AGA ATG 3', and reverse primer: $5^{\prime}$ CGA ATC CAG CGC CAG C 3 (Harada et al., 2005). Primers specific for $\beta$-actin were used as a control (forward: 5' CAA CTT GAT GTA TGA AGG CTT TGG T 3', and reverse: 5' ACT TTT ATT GGT CTC AAG TCA GTG TAC AG 3') (Alfonso et al., 2006). Quantitative real-time PCR was performed in a Cycler (Light Cycler 2.0, Roche) using SYBR Green (DRR041A, Takara). The threshold cycle for each sample was chosen from the linear range and converted to a starting quantity by interpolation from a standard curve run on the same plate for each set of primers. Each sample was assayed in duplicate, and the mRNA levels were normalized for each well to the $\beta$-actin mRNA levels using the $2^{-\Delta \Delta C T}$ method.

ELISA. The vmPFC, IC, BLA, CeA, and hippocampus were dissected at various time points after CS-US pairing $(n=5-6$ per time point) and were stored in microcentrifuge tubes at $-80^{\circ} \mathrm{C}$ until analysis. Brain tissue samples were homogenized in ice-cold lysis buffer containing $137 \mathrm{mM}$ $\mathrm{NaCl}, 10$ mm Tris-HCl, pH 8.0, 1 mм EDTA, pH 8.0, 1\% NP-40, 10\% glycerol, $1 \mathrm{~mm}$ phenylmethylsulphonyl fluoride, $10 \mathrm{mg} / \mathrm{ml}$ aprotinin, 1 $\mathrm{mg} / \mathrm{ml}$ leupeptin, and $0.5 \mathrm{~mm}$ sodium vanadate. The tissue homogenate solutions were centrifuged at $14,000 \times g$ for $5 \mathrm{~min}$ at $4^{\circ} \mathrm{C}$. The supernatants were collected and used for quantification of total protein and BDNF levels. BDNF levels in each region were assessed using a commercially available assay kit from Promega. In brief, flat-bottom plates were coated with the captured BDNF antibodies. The captured BDNF was bound by a second specific antibody, which was detected using a speciesspecific antibody conjugated to horseradish peroxidase as a tertiary reactant. All unbound conjugates were removed by subsequent wash steps according to the Promega protocol. After incubation with chromagenic substrate, color change was measured in an ELISA plate reader at $450 \mathrm{~nm}$.

In situ hybridization. Rats were deeply anesthetized with $10 \%$ chloral hydrate anesthesia ( $4 \mathrm{ml} / \mathrm{kg}$, i.p.) and transcardially perfused with $4 \%$ paraformaldehyde. Brains were removed and postfixed overnight, then equilibrated at $4{ }^{\circ} \mathrm{C}$ in $30 \%$ sucrose/PBS $\left(\mathrm{PO}_{4}{ }^{2-} 0.01 \mathrm{M}, \mathrm{NaCl} 0.15 \mathrm{M}, \mathrm{pH}\right.$ 7.4) for at least $3 \mathrm{~d}$ before sectioning. Brains were sectioned at $40 \mu \mathrm{m}$ thickness on a Microm cryostat (HM 550) at $-20^{\circ} \mathrm{C}$ onto gelatin-coated slides. Every sixth serially obtained section was processed and analyzed for in situ hybridization.

Riboprobes were prepared from an open reading frame of BDNF coding sequence $(387 \mathrm{bp})$ subcloned into a pBluescriptIISK vector. The primers for BDNF were as follows: forward primer $5^{\prime}$ GCC TCC TCT GCT CTT TCT GC 3', and reverse primer 5' CTT ATG AAC CGC CAG CCA AT 3'. Digoxigenin (DIG)-labeled probes were synthesized by T7 or T3 RNA polymerase with the DIG-RNA labeling mix (Roche Diagnostics) using linearized plasmid as template, according to the manufacturer's instructions. In situ hybridization was performed with sense and antisense riboprobes.

The in situ hybridization experiments were performed as described previously (Tongiorgi et al., 1998). Prehybridization was performed at $55^{\circ} \mathrm{C}$ for $60-90 \mathrm{~min}$ in the prehybridization solution. In situ hybridization was carried overnight (at least $16 \mathrm{~h}$ ) at $55^{\circ} \mathrm{C}$. After hybridization, the sections were washed twice in $2 \times$ saline sodium citrate containing $50 \%$ deionized formamide (Roche Diagnostics) at $55^{\circ} \mathrm{C}$ for $30 \mathrm{~min}, 20 \mathrm{~min}$ in $2 \times \mathrm{SSC}$ at $55^{\circ} \mathrm{C}$, and twice in $0.2 \times \mathrm{SSC}$ at $60^{\circ} \mathrm{C}$ for $30 \mathrm{~min}$. Slices hybridized with DIG-labeled riboprobes were processed for detection with anti-DIG antibodies conjugated with alkaline phosphatase (Roche Diagnostics) for $2 \mathrm{~h}$ at room temperature. Finally, sections were incubated in the developing buffer containing NBT (nitro bluetetrazolium) and BCIP (5-bromo-4-chloro-3-indolyl-phosphate) (Roche Diagnostics). To obtain reproducible and comparable results and to avoid saturation of the reaction, alkaline phosphatase development was always performed for exactly $5 \mathrm{~h}$ at room temperature.

Microphotographs of BDNF mRNA were captured by using a Nikon $80 \mathrm{i}$ light microscope equipped with a CCD camera interfaced to a per- 
A

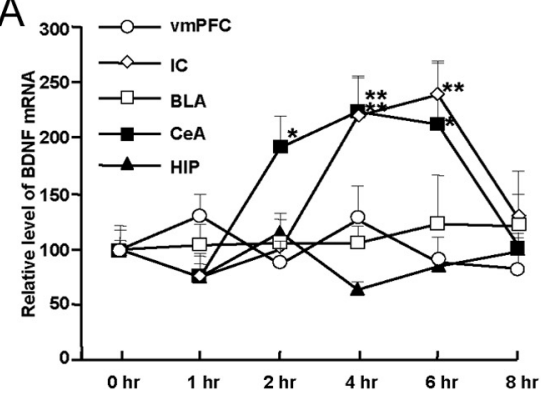

C

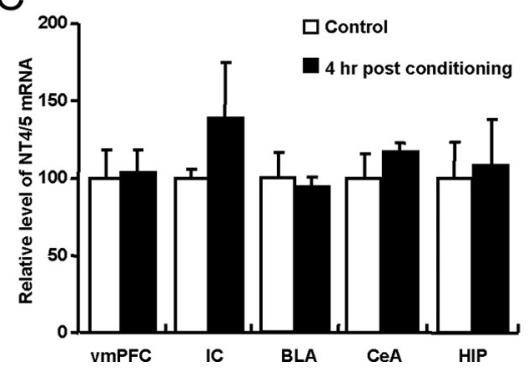

$\mathrm{B}$

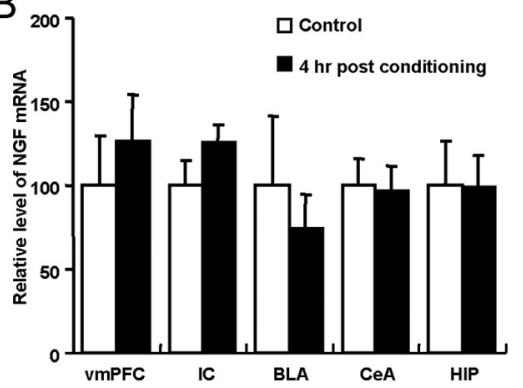

D

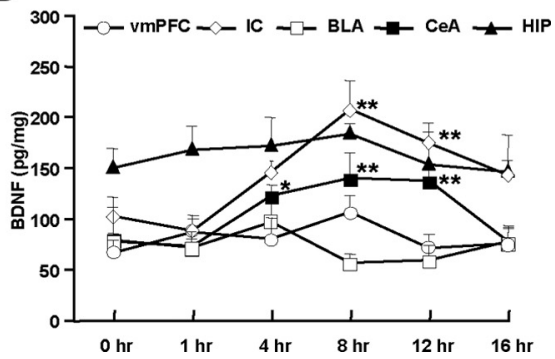

Figure 1. Temporal and spatial changes in neurotrophin expression after CTA conditioning. $\boldsymbol{A}$, Temporal and spatial changes of BDNF mRNA expression after CTA conditioning using real-time $P C R$. Rats were killed at $0,1,2,4,6$, or $8 \mathrm{~h}$ after conditioning, and the relative levels of BDNF mRNA expression normalized to levels at $0 \mathrm{~h}$ in the vmPFC, IC, BLA, CeA, and hippocampus (HIP) are shown ( $n=5$ per time point; ${ }^{*} p<0.05,{ }^{* *} p<0.01$ vs the values at $0 \mathrm{~h}$ time point). $\boldsymbol{B}, \boldsymbol{C}$, Levels of NGF mRNA ( $\left.\boldsymbol{B}\right)(n=5-8$ per group) and NT4/5 mRNA ( $C$ ( $n=6-7$ per group) do not significantly change at $4 \mathrm{~h}$ after CTA conditioning in different brain regions. $\boldsymbol{D}$, Temporal and spatial changes of BDNF protein levels after CTA conditioning using ELISA. Rats were killed at 0,1, 4, 8, 12, or 16 h after conditioning and BDNF protein levels in the vmPFC, IC, BLA, CeA, and HIP are measured $\left(n=5-6\right.$ per time point; ${ }^{*} p<0.05$, ${ }^{* *} p<0.01$ vs the amount at $0 \mathrm{~h}$ time point). All values are presented as mean $\pm \mathrm{SEM}$.

sonal computer. Illumination was adjusted to obtain optimal staining signal and then was kept constant throughout all experiments. Densitometric analysis was performed on the entire frame observed through the camera under the $20 \times$ objective. For each section, data obtained from each animal were normalized on the average density level in their white matter (callosum). For statistical analysis, hybridization density is reported as the average density of all individual animals \pm SEM in each experimental group $(n=5)$. The mean density of all the microphotographs was analyzed with the aid of Image J analysis software.

Immunoprecipitation and immunoblotting. Rats in the experimental group were killed at 1 or $8 \mathrm{~h}$ after CS-US association, while in the control group rats were killed at $0 \mathrm{~h}$ after CTA conditioning. Different from the CS-US associated groups, in the CS control group rats were killed immediately after drinking saccharin. Brain tissues (vmPFC, IC, BLA, and CeA) were dissected and stored at $-80^{\circ} \mathrm{C}$ until homogenization. Tissues were homogenized as described in the procedure for ELISA. The concentration of protein was determined using BCA reagent (Thermo Scientific). For TrkB phosphorylation ( $p$-TrkB) analysis, $5 \mathrm{mg}$ of homogenized lysate was immunoprecipitated using rabbit anti-TrkB antibodies (1:100, Millipore), followed by immunoblotting with mouse anti-phospho-tyrosine antibodies pY99 (1:4000, Santa Cruz Biotechnology) and mouse anti-TrkB antibodies (1:1000, BD Transduction Laboratories), respectively. For total TrkB analysis, homogenized brain lysate was immunoblotted with mouse anti-TrkB antibodies (1:1000, BD Transduction Laboratories) and mouse anti$\alpha$-tubulin (1:10,000, Sigma-Aldrich), respectively. For densitometric analyses, immunoreactive bands were scanned and intensity quantitated using Meta-Morph software (Molecular Devices). Ratios of immunoprecipitated $\mathrm{p}$-TrkB over total TrkB derived from control groups were normalized to 1.0. Values of experimental groups were normalized according to their respective control groups.

Surgical procedures. Rats were anesthetized with $10 \%$ chloral hydrate, restrained in a stereotaxic apparatus (8001, RWD Life Science), and implanted bilaterally with guide cannula (stainless steel, 23 gauge) aimed at $1.0 \mathrm{~mm}$ above the different brain areas following the coordinates below (coordinates in reference to bregma) [infralimbic cortex (IL) region of the vmPFC: anteroposterior (AP), $+3 \mathrm{~mm}$; lateral (L), $\pm 0.5 \mathrm{~mm}$; dorsoven$\operatorname{tral}(\mathrm{V}),-4 \mathrm{~mm}$; IC: AP, $+1.2 \mathrm{~mm} ; \mathrm{L}, \pm 5.3$ $\mathrm{mm} ; \mathrm{V},-5.5 \mathrm{~mm}$; BLA: AP, $-2.58 \mathrm{~mm} ; \mathrm{L}, \pm 5$ $\mathrm{mm} ; \mathrm{V},-7.4 \mathrm{~mm} ; \mathrm{CeA}: \mathrm{AP},-2.2 \mathrm{~mm} ; \mathrm{L}, \pm 4 \mathrm{~mm}$; $\mathrm{V},-7 \mathrm{~mm}$; and hippocampus: AP, $-3.3 \mathrm{~mm}$; $\mathrm{L}$ $\pm 2 \mathrm{~mm}$; $\mathrm{V},-3.4 \mathrm{~mm}$ ) (Paxinos and Watson, 1996). The cannulas were positioned in place with acrylic dental cement and secured with skull screws. A stylus was placed in the guide cannula to prevent clogging. Animals were allowed 1 week to recuperate before being subjected to experimental manipulations.

Microinjection. For microinfusion, the stylus was removed from the guide cannula and a 28 gauge infusion cannula, extending $1.0 \mathrm{~mm}$ from the tip of the guide cannula, was inserted. The infusion cannula was connected via PE20 tubing to a micro-syringe driven by a micro-infusion pump (KDS310, KD Scientific). K252a (dissolved in artificial CSF/0.05\% DMSO, $25 \mu \mathrm{M}, 1$ $\mu \mathrm{l} /$ side, Calbiochem) (Jiang et al., 2001), BDNF antibodies (dissolved in $0.1 \mathrm{M}$ PBS, $1 \mu \mathrm{g} / \mu \mathrm{l}, 0.5$ $\mu \mathrm{l} /$ side, Millipore Bioscience Research Reagents) (Alonso et al., 2002), BDNF ODNs (dissolved in sterile saline, $2 \mathrm{~nm}, 0.5 \mu \mathrm{l} /$ side) (Lee et al., 2004), human recombinant BDNF (hrBDNF) (prepared in sterile saline, $0.25 \mu \mathrm{g} / \mu \mathrm{l}, 1 \mu \mathrm{l} / \mathrm{side}$, PeproTech) (Bekinschtein et al., 2007), ibotenic acid (dissolved in $0.1 \mathrm{M}$ PBS, $10 \mu \mathrm{g} / \mu \mathrm{l}, 0.5$ $\mu \mathrm{l} /$ side, Sigma) (Jarrard, 1989), or their respective vehicles were microinfused into different brain regions. The infusions were performed at a rate of $0.5 \mu \mathrm{l} / \mathrm{min}$, and injection cannulas were left in the position for an additional 2 min after the infusion was completed to minimize dragging of the injected liquid along the injection tract. BDNF ODNs were HPLC-purified phosphorothioate end-capped 18-mer sequences. The ODN sequences used were as follows: BDNF antisense ODN (ASO): 5' TCT TCC CCT TTT AAT GGT 3'; BDNF mis-sense ODN (MSO): 5' ATA CTT TCT GTT CTT GCC 3' (Lee et al., 2004). Both ODNs were phosphorothioated on the three terminal bases of both the $5^{\prime}$ and $3^{\prime}$ ends, which results in increased stability and less toxicity. Compared with the specific matches of BDNF ASO for the rat BDNF mRNA sequence, BDNF MSO, which included the same $18 \mathrm{nt}$ as the ASO but in a scrambled order, did not generate any full matches to identified gene sequences in the database.

Measurement of anxiety-like behavior. Stressed rats were systematically restrained $2 \mathrm{~h}$ per day for 14 consecutive days using cylindrical restrainers, secured at the head and tail ends with large binder clips. Twenty-four hours after the last restraint, anxiety-like behavior was measured using open field (OF) and elevated plus-maze (EPM) tests.

The OF apparatus consists of a $(100 \times 100 \times 50 \mathrm{~cm})$ wood cube with a white floor divided into $5 \times 5$ identical squares. The arena was set up in a dim room under a digital camera, connected to a video recorder. A single rat was placed in the center of the OF arena and left free to explore for $10 \mathrm{~min}$. After each trial, the apparatus was cleaned with a $50 \%$ ethanol solution to prevent olfactory cues. The total number of squares crossed and time spent in the inner $4 \times 4$ squares were recorded to test the locomotor activity and anxiety-like behavior, respectively.

The EPM was constructed of black Plexiglas, consisting of two opposite open arms $(50 \times 10 \mathrm{~cm})$, an open platform $(10 \times 10 \mathrm{~cm})$ in the center, and two opposite closed arms $(50 \times 10 \mathrm{~cm})$ with $40 \mathrm{~cm}$ high opaque walls. The apparatus was raised $50 \mathrm{~cm}$ above the floor and set up under an infrared-sensitive digital camera connected to a video recorder. The test animal was placed in the central platform facing one of the open arms and allowed to explore the apparatus for $5 \mathrm{~min}$. The maze was cleaned with a $50 \%$ ethanol solution and dried after each trial to eliminate possible odor cues left by previous subjects. Anxiety levels were 


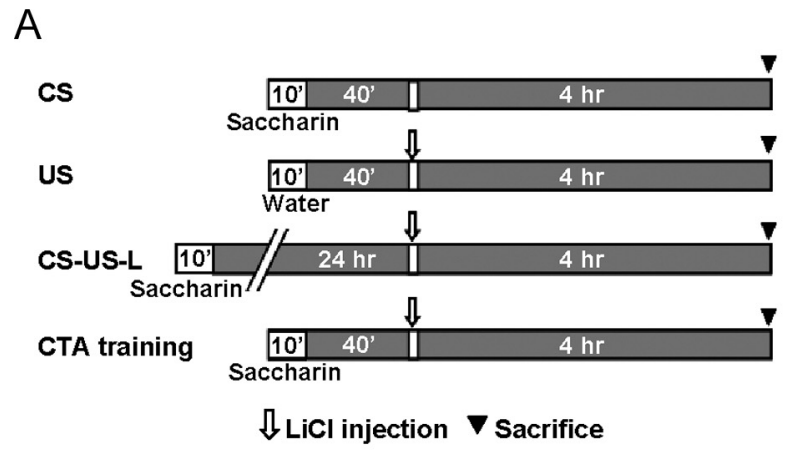

D

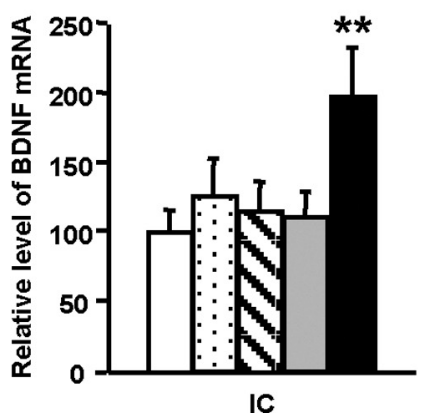

$\mathrm{E}$

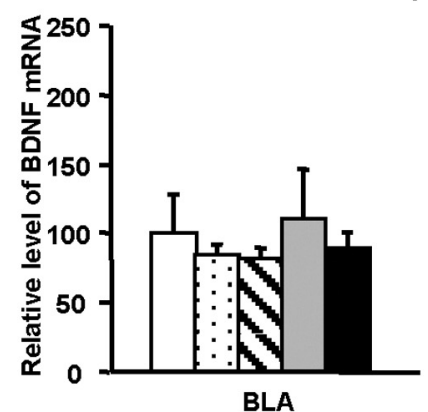

$\mathrm{B}$

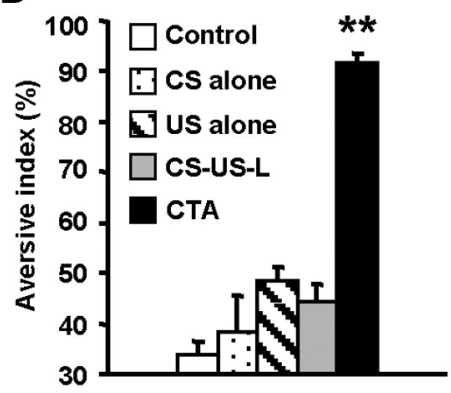

F

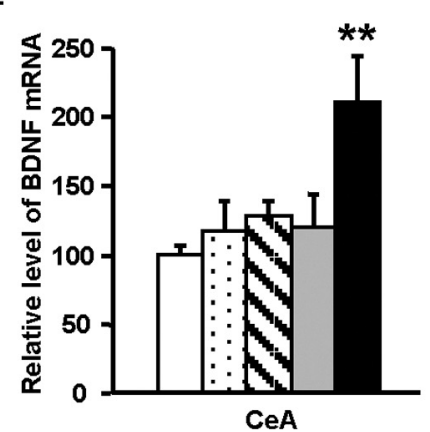

C

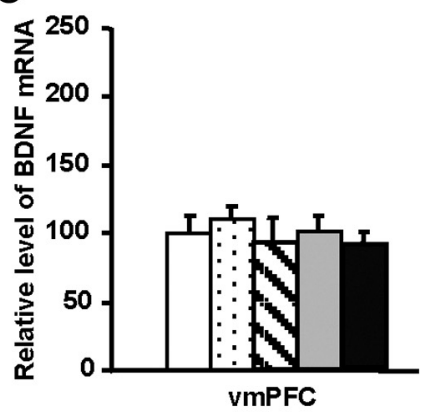

G

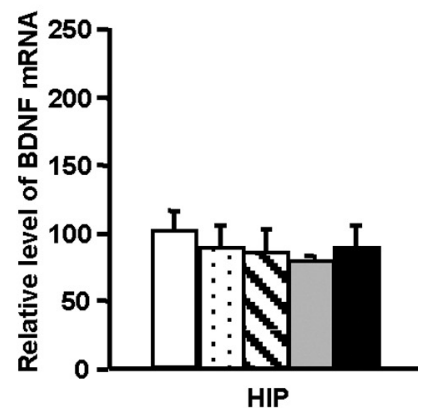

Figure 2. Selective induction of BDNF mRNA expression after associative CTA conditioning. $\boldsymbol{A}$, Schematic of the experimental design for CS-alone, US-alone, CS-US-L, and CTA training groups. All animals were killed at $4 \mathrm{~h}$ after LiCl injection except those in the CS-alone group. $\boldsymbol{B}$, LTM memory formation in the control, CS-alone, US-alone, CS-US-L, and CTA training groups. The behavior tests were performed at $72 \mathrm{~h}$ after LiCl injection except in the control and CS-alone groups. CTA group showed a significantly higher aversion index compared with other control groups ( $n=5-7 \mathrm{per}$ group; $\left.{ }^{* *} p<0.01\right)$. $\mathbf{C}-\mathbf{G}$, Real-time PCR analysis of BDNF mRNA expression in the vmPFC (C), IC (D), BLA (E), CeA (F), and hippocampus (HIP) (G) after CS alone, US alone, CS-US-L, or associative CTA conditioning treatment relative to control levels ( $n=5-6$ per group; ${ }^{* *} p<0.01$ vs control group). All values are presented as mean \pm SEM.

measured by the percentage of both open-arm entries and time spent in open arms.

Histology. At the end of the experiments, rats were deeply anesthetized and $1 \mu \mathrm{l}$ of methylene blue was microinfused. Rats were perfused with saline followed by $4 \%$ paraformaldehyde. Brain sections $(60 \mu \mathrm{m})$ were analyzed to verify the microinfusion sites and the scope of solution diffusion.

Statistical analyses. Data were analyzed with Student's $t$ test or one-way ANOVA, followed by least significant difference post hoc comparisons. The significance level was set to 0.05 for all statistical analyses, and all values in the text and figures represent means \pm SEM. Data analyses were performed using SPSS statistical program, version 10.0.

\section{Results}

Time course of BDNF changes after CTA conditioning

BDNF and its receptor TrkB have been shown to participate in hippocampal-dependent learning and memory. To investigate the role of BDNF in CTA acquisition, we initially examined BDNF gene expression at various time points in distinct brain regions (vmPFC, IC, BLA, CeA, and hippocampus) after CTA conditioning using real-time PCR. As shown in Figure $1 A$, among the five brain regions we analyzed significant changes in BDNF mRNA after CTA conditioning were only observed in the CeA (ANOVA: $F_{(5,24)}=4.459, p=0.005$ ) and IC (ANOVA: $\left.F_{(5,24)}=6.788, p=0.001\right)$. BDNF mRNA increased starting at $2 \mathrm{~h}$ $(p<0.05)$ and peaked at $4 \mathrm{~h}(p<0.01)$ after CTA conditioning in the CeA. BDNF mRNA levels peaked at $6 \mathrm{~h}$ in the IC and began to return to baseline at $8 \mathrm{~h}$ after conditioning. Surprisingly, although the BLA region is believed to play an important role in memory formation, BDNF mRNA level in the BLA did not change significantly subsequent to CTA conditioning (ANOVA: $\left.F_{(5,24)}=0.084, p=0.994\right)$. To test whether other neurotrophins such as NGF and NT4/5 were also increased, we further examined
mRNA levels of these two neurotrophic factors in different brain regions at the $4 \mathrm{~h}$ post-CTA conditioning time point using realtime PCR. Post hoc analysis showed no statistical significance of NGF mRNA (Fig. $1 B$; ANOVA: $F_{(9,47)}=0.413, p=0.922$ ) and NT4/5 mRNA (Fig. $1 C$; ANOVA: $F_{(9,52)}=0.503, p=0.866$ ) compared with the control group, which indicates that only BDNF mRNA levels appeared to show activity-dependent changes after CTA conditioning in specific brain regions.

We next investigated whether the increased BDNF mRNA would lead to BDNF protein level elevation after CTA conditioning. BDNF protein level was examined using ELISA at $0,1,4,8$, 12 , or $16 \mathrm{~h}$ after CTA conditioning. Consistent with the changes of BDNF mRNA, increased BDNF protein levels were detected in the CeA (Fig. $1 D$; ANOVA: $F_{(5,30)}=4.737, p=0.003$ ) and IC (Fig. $1 D$; ANOVA: $F_{(5,30)}=7.016, p<0.001$ ), but not in the BLA (Fig. $1 D$; ANOVA: $F_{(5,30)}=0.584, p=0.712$ ). Compared with the time curve of BDNF mRNA level change, BDNF protein showed a delayed increase, which started at $4 \mathrm{~h}(p<0.05$, vs $0 \mathrm{~h})$ and peaked at $8 \mathrm{~h}(p<0.01$, vs $0 \mathrm{~h})$ postconditioning in the CeA, suggesting that the altered protein synthesis occurred in concert with the increases in gene transcription. The increased BDNF protein levels began to return to baseline at $16 \mathrm{~h}$ after conditioning. The temporal change of BDNF expression in the CeA and IC after CTA conditioning suggests that BDNF in the CeA and IC may be involved in CTA memory formation.

\section{Selective induction of BDNF expression after associative CTA conditioning}

The previous experiments suggest that there are temporal- and spatial-specific changes in BDNF gene expression after CTA conditioning. To further investigate whether BDNF mRNA changes are specific to associative CTA conditioning rather than only ex- 


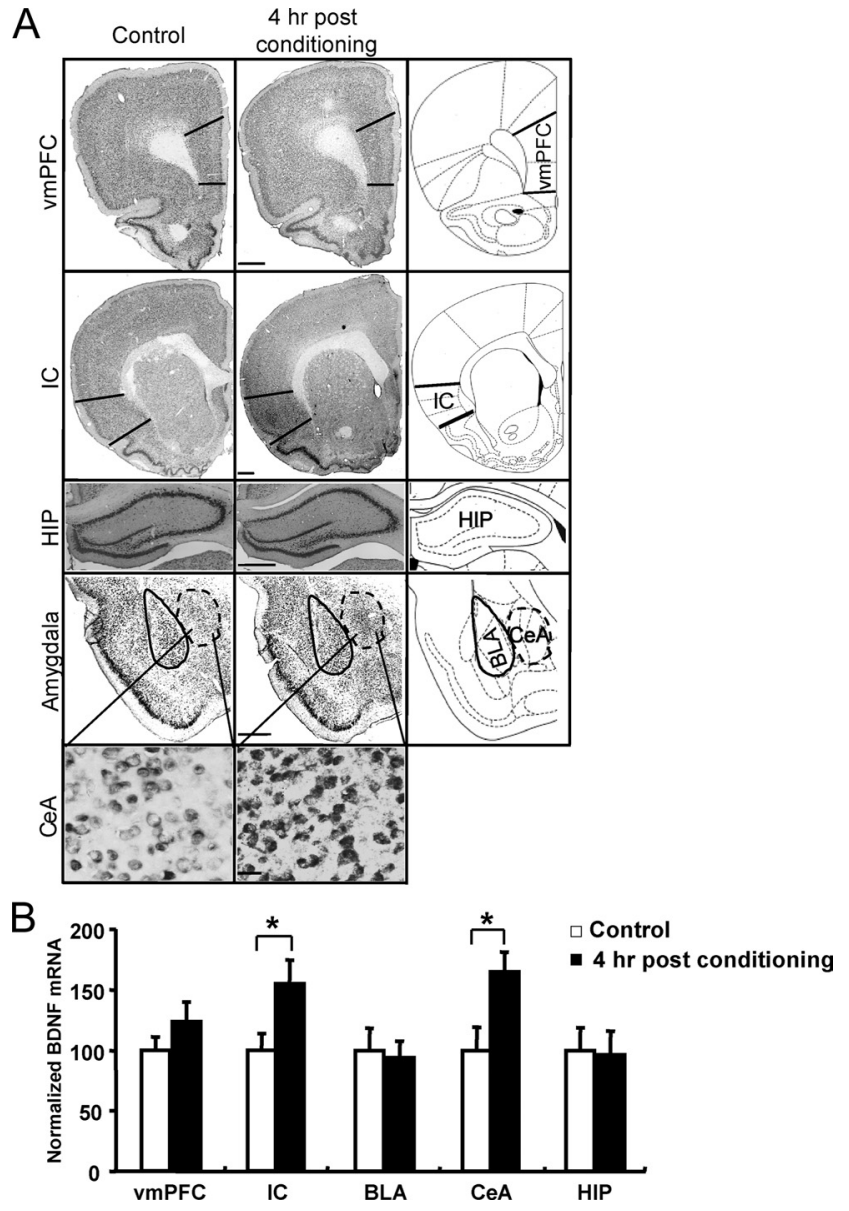

Figure 3. In situ hybridization analysis of regional specific BDNF mRNA increases at $4 \mathrm{~h}$ after CTA conditioning. A, Representative photomicrographs of coronal rat brain sections from CSUS-L control group or CTA conditioning group depicting BDNF mRNA expression in the vmPFC, IC, BLA, CeA, and hippocampus (HIP). Scale bars, $500 \mu \mathrm{m}$. Magnification of sections containing the CeA from CS-US-L control and CTA groups are presented at the bottom. Scale bar, $20 \mu \mathrm{m}$ in the magnified sections at the bottom. $B$, Quantitative analysis of BDNF mRNA from in situ hybridization in the vmPFC, IC, BLA, CeA, and HIP at $4 \mathrm{~h}$ after CTA conditioning normalized to CS-US-L control $\left(n=5\right.$ per group; $\left.{ }^{*} p<0.05\right)$. All values are presented as mean \pm SEM.

posure to either CS or US, rats were separated into the following five groups: control group, CTA group, CS-alone group, USalone group, and CS-US-L group (Fig. $2 A$ ). In the CS-US-L control group, rats received $\mathrm{LiCl}$ injection $24 \mathrm{~h}$ after drinking saccharin, as the long CS-US intervals $(24 \mathrm{~h}$ ) could abolish the CTA learning, and thus precisely assess whether the changes of BDNF gene expression were due to the CS-US association (Gutiérrez et al., 2003). First, we found that only animals that had experienced CS-US pairing showed robust levels of aversion (Fig. $2 B$; ANOVA: $\left.F_{(4,20)}=33.104, p<0.01\right)$, which indicates that CTA memory can be acquired only after the association of CS and US. We chose the $4 \mathrm{~h}$ postconditioning time point to measure BDNF mRNA level on the basis of our previous results. Levels of BDNF mRNA were only significantly elevated in the associative CTA conditioning group in the CeA (Fig. $2 F$; ANOVA: $F_{(4,21)}=$ $4.219, p<0.05$ ) and the IC (Fig. $2 D$; ANOVA: $F_{(4,28)}=2.760, p<$ $0.05)$ relative to control, which suggests that the increased BDNF gene expression during CTA formation is specific to the association of CTA, regardless of CS or US modality. Consistent with our previous observations, no significant changes in BDNF gene expression have been found in the BLA (Fig. 2E; ANOVA: $\left.F_{(4,26)}=0.335, p=0.852\right)$, vmPFC (Fig. $2 C$; ANOVA: $F_{(4,25)}=$
$0.427, p=0.788$ ), or hippocampus (Fig. $2 G$; ANOVA: $F_{(4,29)}=$ $0.256, p=0.903)$.

Furthermore, a sensitive nonradioactive in situ hybridization (Tongiorgi et al., 1998) was used to investigate the spatial regulation of BDNF mRNA in different brain regions after CTA conditioning. Representative photomicrographs of BDNF in situ hybridization from rats of the CS-US-L control group and associative CTA conditioning group were shown in Figure 3A. BDNF mRNA was widely distributed in the whole brain and appeared to be localized in neuronal cytoplasm and dendrites under higher magnification, which is consistent with previous studies (Tongiorgi et al., 2004). However, the BDNF mRNA level changes in different brain regions were strikingly different after CTA conditioning. Statistical analysis of hybridization density level revealed that there was a dramatic accumulation of BDNF mRNA in the CeA ( $t$ test, $p<0.05)$ and IC ( $t$ test, $p<0.05)$ at $4 \mathrm{~h}$ after CTA conditioning compared with the control group (Fig. $3 B$ ). The elevated BDNF mRNA was also detected in the nucleus of accumbens and ventral posteromedial thalamic nucleus (data not shown). Meanwhile, no significant changes were found in the BLA ( $t$ test, $p=0.790)$, vmPFC ( $t$ test, $p=0.78$ ), or hippocampus ( $t$ test, $p=0.874)$. As a control, sections hybridized with the BDNF sense riboprobes yielded no signal (data not shown). Together, these findings further confirm our real-time PCR results that there are temporal- and spatial-specific changes in BDNF gene expression after CTA conditioning, which suggests that $\mathrm{BDNF}$ in different brain regions may play different roles in CTA memory formation.

\section{TrkB is activated after CTA conditioning with increased BDNF secretion and synthesis}

The release of BDNF and its binding to TrkB receptor, leads to the dimerization and autophosphorylation of tyrosine residues in the intracellular domain of the receptor and subsequent activation of downstream signaling molecules (Kaplan and Miller, 2000). Though both BDNF and NT4/5 can bind to and induce TrkB receptor phosphorylation, we have previously found that NT4/5 expression levels did not show statistically significant changes after CTA conditioning, thus the phosphorylation of TrkB was likely triggered by the release of BDNF during the CTA process. To test whether TrkB activation was accompanied with BDNF protein increase, tissues were dissected at $8 \mathrm{~h}$ after CTA conditioning. $\mathrm{p}$-TrkB levels normalized to total TrkB were measured by immunoprecipitation and immunoblotting. Quantitative densitometric analyses of $\mathrm{p}$-TrkB receptors showed elevated levels of p-TrkB in the CeA (Fig. $4 B$; ANOVA: $F_{(2,7)}=8.34, p<0.05$; post hoc: control vs $8 \mathrm{~h}, p<0.05)$ and IC (Fig. $4 B$; ANOVA: $F_{(2,9)}=4.771, p<0.05$; post hoc: control vs $\left.8 \mathrm{~h}, p<0.05\right)$, but not in the BLA (Fig. $4 B$; ANOVA: $F_{(2,9)}=2.517, p=0.135$ ) after conditioning. To investigate whether TrkB was activated only subsequent to the increased BDNF expression, tissues were dissected at $1 \mathrm{~h}$ after CTA conditioning when both BDNF mRNA and protein levels showed no change. Interestingly, post hoc analysis showed significantly enhanced $\mathrm{p}$-TrkB levels in the $\mathrm{CeA}(p<$ $0.01)$ and IC $(p<0.05)$ at $1 \mathrm{~h}$ postconditioning, which suggested induced rapid activity-dependent BDNF release in advance of the increased BDNF synthesis associated with CTA training. Collectively, the immediate activation of TrkB in the same brain regions with increased BDNF expression, suggests that BDNF secretion and synthesis may be spatially and temporally involved in CTA memory formation. 

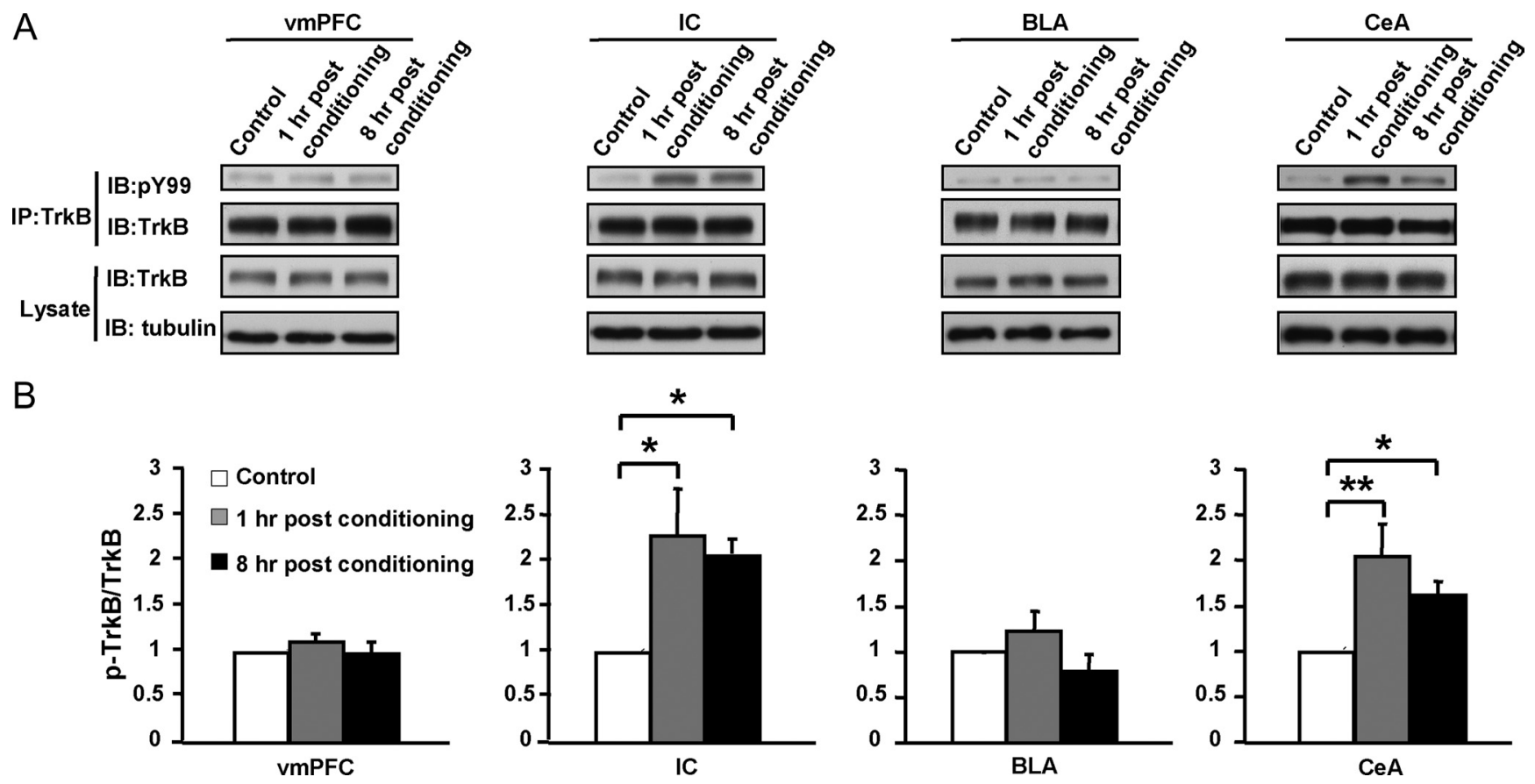

Figure 4. Spatial changes in TrkB phosphorylation levels after CTA conditioning. A, Lysates of vmPFC, IC, BLA, and CeA were subjected to immunoprecipitation with rabbit anti-TrkB antibodies and immunoblotted with pY99 antibodies (top panel). Immunoprecipitation of total TrkB was confirmed by immunoblotting with mouse anti-TrkB antibodies (second panel). In addition, TrkB levels from the respective initial lysates were verified by mouse anti-TrkB antibodies (third panel), and $\alpha$-tubulin was used to confirm equivalent protein loading (bottom panel). $\boldsymbol{B}$, Densitometric analyses showing levels of $\mathrm{p}$-TrkB receptor (in the vmPFC, IC, BLA, and (eA) relative to total TrkB obtained from immunoprecipitation at 1 and $8 \mathrm{~h}$ after CTA conditioning normalized to the control. Error bars represent SEM $\left(n=3-4\right.$ per group; $\left.{ }^{*} p<0.05,{ }^{* *} p<0.01\right)$.

\section{Blockade of Trk in the IC and CeA but not in the BLA and vmPFC by K252a impairs CTA STM and LTM}

Although the previous experiments demonstrate that BDNF secretion and the subsequent BDNF synthesis are specifically regulated during CTA learning, they do not address the question of whether endogenous BDNF is functionally necessary for CTA acquisition. To assess whether BDNF triggered TrkB activation is required for CTA memory formation, K252a, a potent inhibitor of Trk receptors, or the same volume of vehicle was bilaterally infused into specific brain regions 30 min before saccharin administration (Fig. 5A). Histological verification of the scopes of the diffused solution in different brain regions is shown in supplemental Fig. S1 (available at www.jneurosci.org as supplemental material). No effect was found when K252a was microinjected into the BLA (Fig. $5 B, C$; $t$ test; STM, $p=0.401 ; \mathrm{LTM}, p=0.831$ ), a region implicated in fear memory acquisition (Lee and Kim, 1998; Rattiner et al., 2004; Laurent and Westbrook, 2009), indicating that BDNF in this region does not contribute to CTA memory formation. However, inhibition of Trk in the CeA attenuated both CTA STM and LTM (Fig. $5 B, C$; $t$ test, STM, $p=0.001$; LTM, $p<0.01$ ). To exclude the possibility that the BLA subnuclei itself is not involved in CTA formation, an additional BLA lesion experiment was performed by microinjection of an excitotoxin, ibotenic acid, into BLA to selectively destroy cells but not fibers of passage (Jarrard, 1989, 2002). In contrast to sham operated rats, rats that received bilateral ibotenic acid injections into BLA $48 \mathrm{~h}$ before conditioning (Fig. $5 D$ ) showed deficits in both CTA STM and LTM (Fig. $5 E$; $t$ test, STM, $p<0.001$; LTM, $p=0.012$ ), which suggested that BLA participates in the neural networks related to CTA formation. Together, these data indicate that BDNF in the two subnuclei of amygdala have different roles in CTA memory formation.

The IC is a region in the temporal cortex that has been implicated in the acquisition and storage of different aversive moti- vated learning tasks like spatial maze, inhibitory avoidance, and CTA (Bermudez-Rattoni and McGaugh, 1991; BermúdezRattoni, 2004). Our results showed that microinfusion of K252a into the IC before conditioning impaired both the STM and LTM of CTA (Fig. $5 B, C$; $t$ test; STM, $p<0.001$; LTM, $p<0.001$ ). In contrast, microinfusion of K252a into the IL of the vmPFC (Fig. $5 B, C$; $t$ test; STM, $p=0.481$; LTM, $p=0.51$ ) or hippocampus (Fig. $5 B, C$; $t$ test; STM, $p=0.558$; LTM, $p=0.866$ ) has no effect on CTA memory formation. Together with our previous findings, these results suggest that BDNF is not only selectively induced by CTA conditioning in specific brain regions, but also spatially involved in STM and LTM of CTA.

\section{BDNF secretion and synthesis in the CeA are respectively involved in CTA STM and LTM}

Since K252a is a pharmacological inhibitor of all Trk receptors and also may have nonspecific effects, BDNF ASO and anti$\mathrm{BDNF}$ blocking antibodies were further used to specifically investigate the role of BDNF in CTA memory formation. More importantly, BDNF ASO and anti-BDNF blocking antibodies could respectively block de novo BDNF synthesis and neutralize endogenously released BDNF, which allow us to distinguish the roles of BDNF synthesis and secretion in memory formation. $\mathrm{BDNF} A \mathrm{SO}$ or BDNF antibodies were microinfused into the CeA 15 min before CTA conditioning (Fig. 6A). Compared with BDNF MSO injection, real-time PCR analysis showed that BDNF ASO microinfusion abolished the increased BDNF mRNA levels in the CeA at $4 \mathrm{~h}$ postconditioning (Fig. $6 \mathrm{~B}$; ANOVA: $F_{(2,12)}=$ 5.315, $p=0.022$; post hoc: control vs BDNF ASO, $p=0.804$; BDNF MSO vs BDNF ASO, $p=0.012$ ). However, BDNF ASO administration could not inhibit the elevated p-TrkB level at $1 \mathrm{~h}$ postconditioning in the CeA (Fig. $6 C$; ANOVA: $F_{(4,14)}=15.662$, $p<0.001$; post hoc: BDNF MSO vs BDNF ASO, $1 \mathrm{~h}, p=0.218$; 


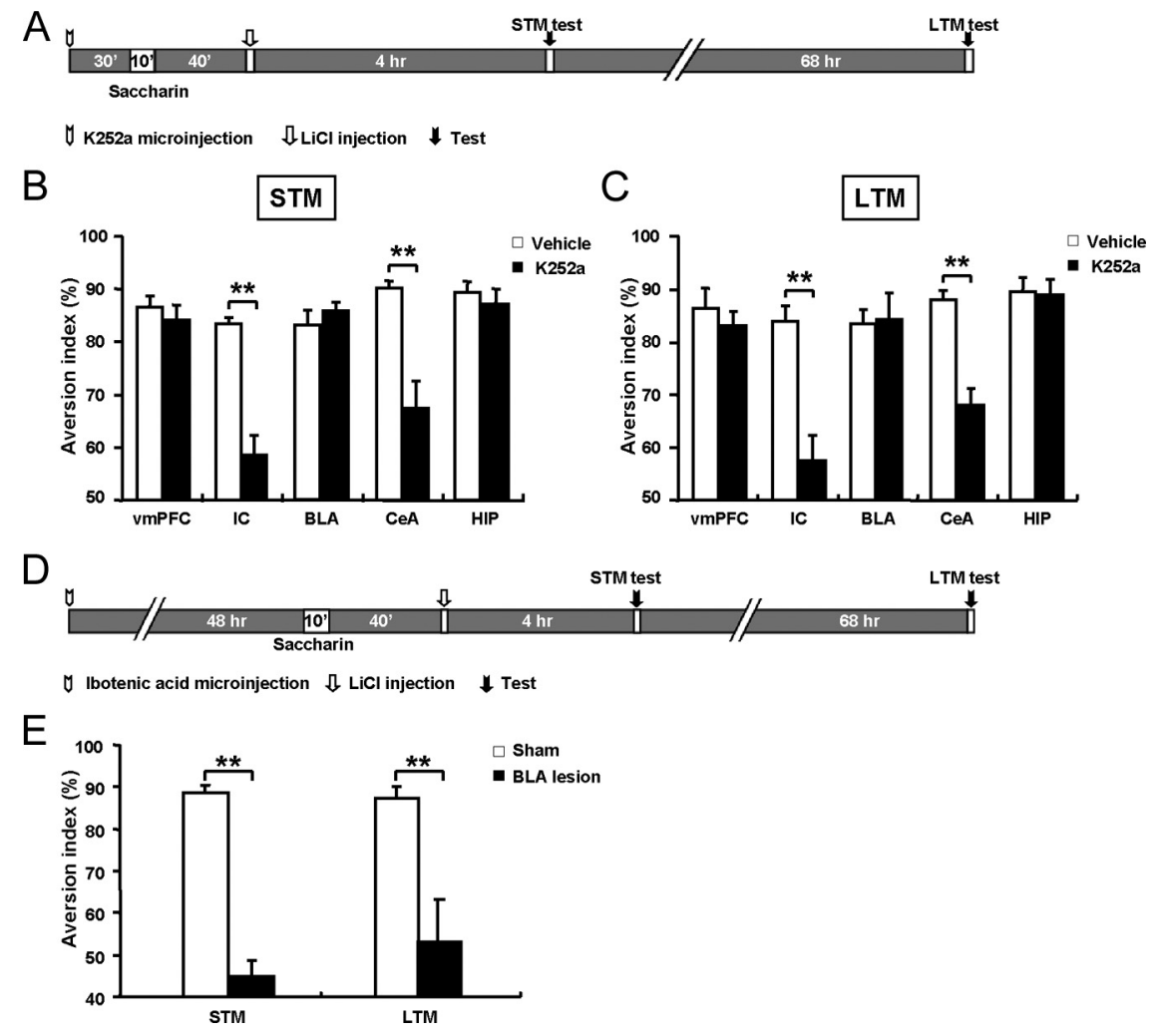

Figure 5. Effects of K252a on CTA STM and LTM formation. A, Schematic representation of the behavior protocol to evaluate the effect of K252a on CTA STM and LTM formation. Rats received bilateral microinfusion of K252a or vehicle into IL, IC, BLA, CeA, or hippocampus (HIP) 30 min before CTA conditioning, and the STM and LTM tests were performed at 4 and $72 \mathrm{~h}$ postconditioning. $\boldsymbol{B}$, C, Spatial involvement of BDNF/TrkB signaling in CTA STM $(\boldsymbol{B})$ and LTM memory formation $(\boldsymbol{C})$ revealed by pretraining infusion of K252a into different brain regions is shown. The aversion index is presented as mean \pm SEM from analysis of $5-8$ rats per group $\left({ }^{* *} p<0.01\right) . \boldsymbol{D}$, Schematic representation of the BLA lesion experimental design. Rats received bilateral microinfusions of vehicle or ibotenic acid $48 \mathrm{~h}$ before CTA conditioning, and the STM and LTM tests were performed 4 and $72 \mathrm{~h}$ later. $E$, BLA lesions produce impaired CTA STM and LTM $\left(n=5-7\right.$ per group; $\left.{ }^{* *} p<0.01\right)$.

$8 \mathrm{~h}, p=0.001$ ), which suggests that BDNF ASO treatment could block BDNF synthesis but has no effect on the rapid BDNF secretion induced by CTA conditioning. In contrast, infusion of BDNF antibodies into the CeA prevented p-TrkB elevation at 1 and $8 \mathrm{~h}$ after conditioning (Fig. $6 C$; ANOVA: $F_{(4,10)}=9.377, p=$ $0.002)$. Furthermore, BDNF antibody administration also inhibited BDNF gene expression at $4 \mathrm{~h}$ after conditioning (Fig. $6 \mathrm{~B}$; ANOVA: $\left.F_{(2,12)}=10.795, p=0.002\right)$. These data suggest that BDNF antibody infusion could block both the rapid TrkB phosphorylation and the subsequent BDNF synthesis in the CeA after CTA conditioning and that TrkB activation is necessary for the observed increases in BDNF synthesis.

To determine the role of BDNF secretion and synthesis in CTA memory formation, both STM and LTM were measured after delivering BDNF ASO or antibodies in the amygdala. We found selective impairment of LTM, but not STM, after blocking de novo BDNF expression by infusion of BDNF ASO in the CeA (Fig. $6 D$; ANOVA: $F_{(3,28)}=18.485, p<0.001$; post hoc: LTM: BDNF MSO vs BDNF ASO, $p<0.01)$. Administration of BDNF antibodies in the CeA disrupted both STM and LTM (Fig. 6E; ANOVA: $F_{(3,28)}=12.574, p<0.001$; post hoc: vehicle vs BDNF antibody, $p<0.01)$. However, delivery of BDNF ASO or antibodies into the BLA produced no effect on STM and LTM (Fig. $6 D, E)$. Together these data demonstrate that in the CeA activitydependent BDNF secretion is required for STM, while the subsequent de novo BDNF synthesis is involved in LTM formation.
It has been shown previously that BDNF ASO infusion into the CeA induced anxietylike behaviors (Pandey et al., 2006). To examine whether changes in anxiety levels would modify CTA memory formation, a chronic restraint stress (CRS) protocol (2 $\mathrm{h} / 14 \mathrm{~d}$ ), which could produce anxiety-like behavior (Kim and Han, 2006), was used, and anxiety-like behaviors were evaluated $24 \mathrm{~h}$ after the CRS (Fig. 7A). Compared with the unstressed rats, stressed animals had decreased exploratory behavior as demonstrated by a reduction in the time spent in the center compartment in the OF test (Fig. $7 B$; $t$ test, $p<0.01$ ), as well as a significant decrease in the percentage of open-arm entries and the percentage of time spent in open arms in the EPM test (Fig. 7C; $t$ test, $p<0.01$ ). These results suggested that the CRS procedure produced anxiety-like behaviors. Next, CTA conditioning was conducted and the STM and LTM were evaluated (Fig. 7A). In contrast to the elevated anxiety-like behaviors, there were no significant differences in CTA STM (Fig. $7 D$; $t$ test, $p=0.283$ ) and LTM ( $t$ test, $p=$ 0.254 ) between the stressed and unstressed groups. These series of experiments suggest that stress-induced increased anxiety level has no effect on the CTA STM and LTM memory formation.

\section{BDNF synthesis in the CeA is required for CTA consolidation}

Since our previous results have shown that BDNF participated in CTA LTM formation, we next investigated the functional role of BDNF in different memory processes, such as acquisition, consolidation, or retrieval by varying the time point of BDNF antibody microinjection into the CeA. BDNF antibodies were infused into the CeA at $1 \mathrm{~h}$ post-CTA conditioning and both the STM and LTM were measured (Fig. $8 A$ ). We found the intact STM and impaired LTM (Fig. 8 B; ANOVA: $F_{(3,28)}=7.556$, $p=0.001$; post hoc: vehicle vs BDNF antibody, STM, $p=0.934$; LTM, $p<0.01$ ) after infusion of BDNF antibodies at $1 \mathrm{~h}$ postconditioning, which suggests that the increased BDNF synthesis is required for the CTA memory consolidation and the rapid BDNF secretion within $1 \mathrm{~h}$ after CTA conditioning is involved in CTA memory acquisition. LTM impairment could also be due to memory retrieval deficit. In an additional experiment, we microinjected BDNF antibodies into the CeA 15 min before LTM test and detected similar levels of LTM compared with vehicle group (Fig. $8 A, B$; $t$ test, $p=0.151$ ). Thus, BDNF is not necessary for the retrieval of acquired CTA memory. Overall, these results suggest that BDNF secretion and synthesis in the CeA are respectively involved in CTA memory acquisition and consolidation, but not in memory retrieval.

\section{BDNF could enhance CTA memory formation}

Because the previous experiments demonstrated that BDNF signaling in the CeA is necessary for CTA learning, we wanted to know whether exogenous BDNF administration is sufficient for CTA memory formation. Here, we used a weak CTA training 
protocol in which rats were injected with a lower concentration of $\mathrm{LiCl}$ ( $\mathrm{LiCl}$ concentration $0.05 \mathrm{M}$ ) compared with normal CTA conditioning ( $\mathrm{LiCl}$ concentration $0.15 \mathrm{M}$ ). Post hoc comparisons revealed that rats in the weak training group showed significantly attenuated STM and LTM memory, compared with the normal conditioning group (Fig. 9A; ANOVA: STM, $F_{(2,12)}=$ 72.267, $p<0.001$; LTM, $F_{(2,12)}=48.662$, $p<0.001)$. Paralleling the attenuated memory, we found that weak training abolished the increased BDNF gene expression at 4 $\mathrm{h}$ postconditioning (Fig. 9B; ANOVA: $F_{(2,12)}=4.275, p=0.04$; post hoc: CS vs weak, $p=0.563$; CS vs normal, $p<0.05$ ) and led to significantly decreased TrkB phosphorylation at 1 and $8 \mathrm{~h}$ after CTA conditioning in the CeA (Fig. 9C; ANOVA: $F_{(4,10)}=25.817, p<0.001 ;$ post hoc: weak vs normal, $p<0.001)$ compared with normal CTA group, which further confirms our previous conclusion that BDNF signaling in the CeA plays an important role in CTA memory formation. Next, exogenous BDNF or vehicle was microinfused into CeA immediately after weak CTA training, and the STM and LTM of CTA were evaluated (Fig. 9D). We found that exogenous BDNF infusion could rescue the attenuated STM (Fig. 9E; ANOVA: $F_{(2,21)}=27.681$, $p<0.001$; post hoc: weak + hrBDNF vs normal + vehicle, $p=0.477$ ) and LTM (Fig. 9E; ANOVA: $F_{(2,21)}=16.860, p<0.001$; post hoc: weak + hrBDNF vs normal + vehicle, $p=0.238$ ) caused by weak training to normal levels compared with the normal conditioning group. These results suggest that BDNF in the CeA is not only necessary but also sufficient for CTA memory formation.

\section{Discussion}

The purpose of this study is to investigate the spatial involvement of BDNF secretion and synthesis in CTA memory formation. We provided evidence that increased BDNF secretion and synthesis were temporally induced in specific brain regions after associative CTA conditioning. Inhibition of BDNF signaling in selective brain regions could block CTA acquisition. Moreover, we found that activity-dependent BDNF secretion and synthesis are respectively involved in STM and LTM of CTA. Finally, we demonstrated that the infusion of exogenous BDNF into CeA could enhance CTA memory formation.

Anatomical and pharmacological studies have highlighted the involvement of several brain structures (e.g., PBN, amygdala, IC, vmPFC) and cellular processes [e.g., expression of immediate early genes, Ras-mitogen-activated protein kinase (MAPK) signaling pathway, protein synthesis] in CTA learning (Welzl et al., 2001). Our data provide several new insights into the spatial-specific involvement of BDNF secretion and synthesis in the CTA memory process. First, we found that BDNF expression was temporally induced in selective brain regions after CTA conditioning, whereas levels of other neurotrophins such as NGF and NT4/5 did not change. BDNF has been extensively studied in hippocampal- and amygdaladependent learning and memory (Kesslak et al., 1998; Hall et al., 2000; Rattiner et al., 2004; Chhatwal et al., 2006). However, little is known about the role of BDNF in hippocampalindependent cortical memory process. Elevated BDNF expression levels in the CeA and IC during CTA acquisition have been found after associative CS-US pairings, suggesting that an interaction of the representations of the CS and US is obligatory for BDNF involvement in novel taste learning. The differential changes of BDNF expression in the two subnuclei of amygdala during CTA acquisition imply that BDNF may play distinct roles in CTA memory formation in different brain regions. In addition, we found increased phosphorylation of $\mathrm{BDNF}$ receptor, TrkB, at the time point before and following increased BDNF synthesis in the CeA and IC, which suggests that associative CTA learning could first induce the rapid re- 


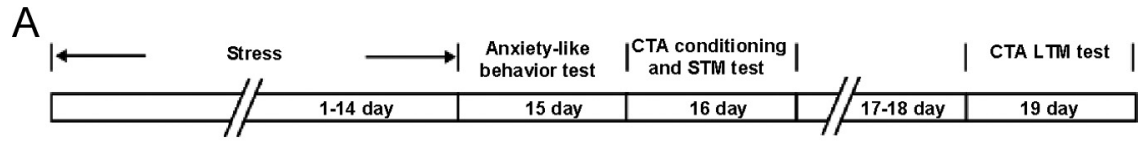

B
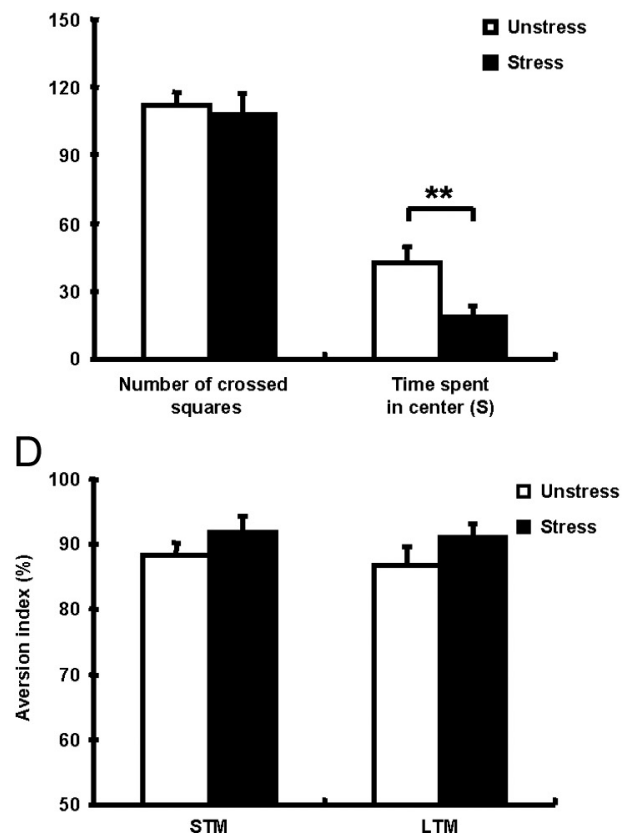

Figure 7. Effect of chronic restraint stress-induced elevated anxiety on CTA memory formation. $A$, Schematic representation of the behavior protocol. Rats were restrained for 14 consecutive days $(2 \mathrm{~h} / \mathrm{d}) . \boldsymbol{B}-\boldsymbol{D}$, Anxiety-like behaviors $(\boldsymbol{B}, \boldsymbol{C})$ and CTA conditioning $(\boldsymbol{D})$ were respectively performed at 24 and $48 \mathrm{~h}$ after the last stress. CTA STM and LTM tests were performed at 4 and $72 \mathrm{~h}$ after conditioning. $\boldsymbol{B}$, Number of squares crossed and time spent in the center in the open field test in the stressed and unstressed rats. $C$, Percentage of time spent in the open arm and percentage of open-arm entries in the plus-maze test in the stressed and unstressed rats. $\boldsymbol{D}$, Aversion index in the CTA STM and LTM tests in the stressed and unstressed rats. All results are presented as the mean \pm SEM determined from analysis of $7-10$ rats per group $\left({ }^{* *} p<\right.$ $0.01)$.

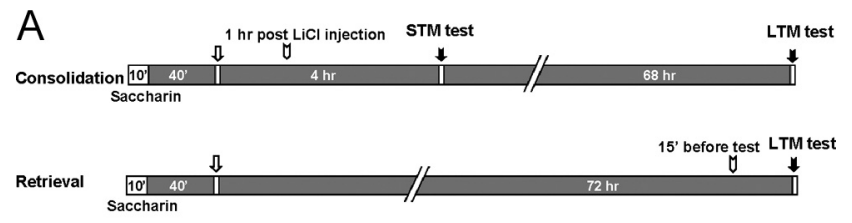

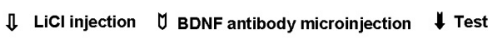

B

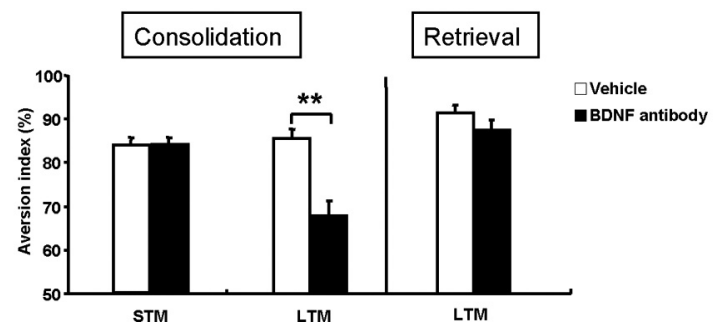

Figure 8. Effects of BDNF antibodies on CTA memory consolidation and retrieval in the CeA. $\boldsymbol{A}$, Schematic representation of the behavior protocol to evaluate the effect of BDNF on CTA consolidation and retrieval. $\boldsymbol{B}$, To investigate the role of BDNF in CTA memory consolidation, rats received bilateral CeA microinfusion of BDNF antibodies or vehicle at $1 \mathrm{~h}$ post-CTA conditioning, and the STM and LTM tests were performed at 4 and $72 \mathrm{~h}$ after conditioning, respectively $\left({ }^{* *} p<0.01\right)$. To investigate the effect of BDNF on CTA memory retrieval, BDNF antibodies or vehicle were administrated into the CeA $15 \mathrm{~min}$ before the LTM test. The values represent the mean \pm SEM determined from analysis of 8 rats per group. lease of preexisting BDNF, followed by increased BDNF synthesis.

Second, we found that BDNF in selective brain regions was differentially involved in CTA memory formation. Notably, we found that BDNF/TrkB signaling in the CeA and BLA, two subnuclei of amygdala, play distinct roles in CTA memory formation. Intra-CeA infusion of K252a, BDNF ASO, or BDNF antibodies significantly impaired CTA memory formation; however, inhibition of BDNF/ TrkB signaling in the BLA had no effect. Previous studies have shown diverse molecular mechanisms within the CeA and BLA to be implicated in mediating CTA acquisition. Local microinfusion of the protein synthesis inhibitor anisomycin or the $\beta$-adrenergic antagonist propranolol into the CeA but not BLA during the training session impaired CTA memory (Bahar et al., 2003); whereas, intra-BLA infusions of NMDA antagonist MK-801 or D-AP5 [D-(2)-2-amino-5-phoshonovaleric acid], AMPA antagonist CNQX (6cyano-7-nitro-quinoxaline-2,3-dione), or metabotropic glutamate receptors antagonist (S)-MCPG [(S)- $\alpha$-methyl-4-carboxyphenylglycine] affected CTA memory formation (Yamamoto and Fujimoto, 1991; Tucci et al., 1998; Yasoshima et al., 2000). Our study demonstrates that BDNF in the CeA, but not BLA, is necessary for CTA memory formation. Our data are also consistent with previous findings that microinjection of antisense oligodeoxynucleotides against cAMP response element-binding protein (CREB) into CeA-impaired CTA formation (Lamprecht et al., 1997), as BDNF is known to activate CREB and CREB plays a central role in mediating BDNF responses in neurons (Finkbeiner et al., 1997). Although blocking BDNF signaling in the BLA has been shown to impair amygdaladependent tasks such as fear-potentiated startle (Rattiner et al., 2004), BDNF in the BLA does not appear to affect memory formation in hippocampal-independent nondeclarative CTA memory tests, suggestive of selective roles for BDNF in different learning tasks. In addition, we found that BDNF/TrkB signaling in the IC, but not hippocampus, is essential for CTA memory formation. The role of the IC in CTA memory formation has been demonstrated in many studies by microinfusion of NMDAR or muscarinic acetylcholine receptor antagonist, MAPK inhibitor, or protein synthesis inhibitor anisomycin (Rosenblum et al., 1993, 1997; Naor and Dudai, 1996; Berman et al., 1998). Moreover, several studies have confirmed the important role of BDNF in the IC in CTA memory. Application of exogenous BDNF in IC in anesthetized adult rats induces a lasting potentiation of synaptic efficacy and reverses the CTA memory deficits produced by the inhibition of protein synthesis (Escobar et al., 2003; MoguelGonzález et al., 2008). In addition, BDNF microinfusion into the IC can enhance the CTA retention (Castillo et al., 2006), which is dependent on the activation of both MAPK and phos- 
phatidylinositol-3-kinase (Castillo and Escobar, 2011). However, the role of endogenous BDNF in the IC in CTA memory has not been addressed in these studies. Here, we found that BDNF in the IC was required for CTA STM and LTM formation. In contrast, inhibition of BDNF/TrkB signaling in the hippocampus had no effect on CTA memory formation, which is consistent with a previous report showing that hippocampal integrity is not required for the CTA memory process (Gallo and Cándido, 1995).

Third, this is the first study demonstrating that the activity-dependent rapid BDNF secretion and the subsequent increased BDNF expression in CeA after CTA conditioning are differentially involved in STM and LTM. Although BDNF has been shown to play an important role in LTM, it has not been established whether BDNF is involved in STM formation. Infusion of BDNF ASO in the hippocampus before contextual fear conditioning had no effect on STM; whereas, functional blocking of BDNF availability by delivering BDNF antibodies in the hippocampus did impair STM of inhibitory avoidance training (Alonso et al., 2002; Lee et al., 2004). These conflicting results may be attributable to the different approaches used to inhibit BDNF function. In our study, we found that BDNF ASO microinfusion could block de novo BDNF synthesis but had no effect on the rapid BDNF secretion induced by CTA conditioning; however, BDNF antibody administration could neutralize the secreted BDNF and block the following TrkB phosphorylation. Our study indicates that the increased BDNF secretion and synthesis in the CeA were respectively required for CTA STM and LTM, and therefore explained the discrepancy in previous studies. Furthermore, we found that BDNF was required for the acquisition and consolidation, but not the retrieval, of CTA memory in the CeA by varying the delivering time of BDNF antibodies. Interestingly, our results suggest that the elevation of $\mathrm{p}-\mathrm{TrkB}$ is necessary for the subsequent increased BDNF gene transcription, implying that the initial release of BDNF accompanied by TrkB activation triggers a cascade of BDNF synthesis resulting in subsequent BDNF-mediated consolidation.

Finally, we showed that exogenous BDNF administration in the CeA could enhance CTA memory, which suggests that BDNF in the CeA is not only necessary but also sufficient for CTA learning. It has been reported that the transgenic mouse overexpressing TrkB receptor in the postnatal neurons could lead to increased TrkB phosphorylation and improved CTA learning (Koponen et al., 2004). In addition, previous reports have shown that microinfusion of BDNF into IC before CTA training could enhance the CTA learning (Castillo et al., 2006)

E
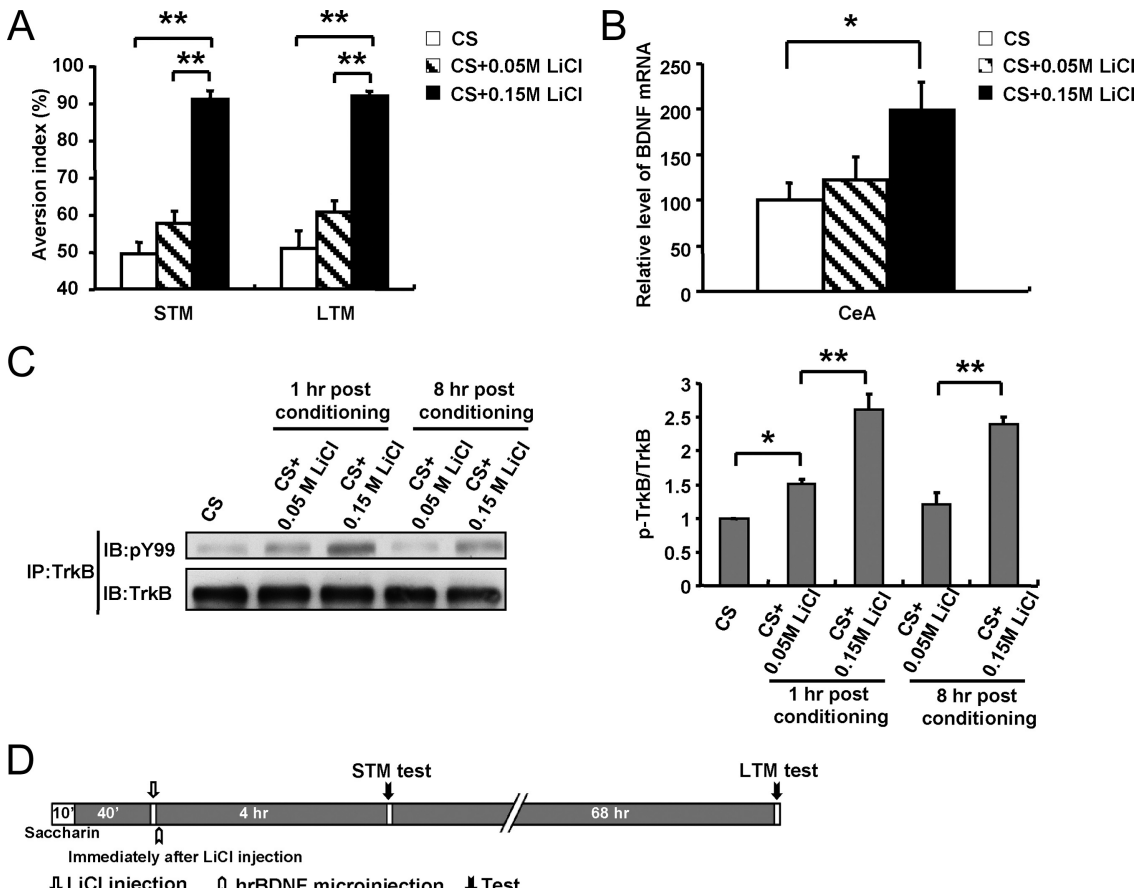

Figure 9. Exogenous BDNF administration in the CeA could rescue CTA memory deficits. A, CTA STM and LTM formation in the CS (CS alone), weak CTA (CS + $0.05 \mathrm{~m} \mathrm{LiCl),} \mathrm{and} \mathrm{normal} \mathrm{CTA} \mathrm{(CS} \mathrm{+} 0.15 \mathrm{~m} \mathrm{LiCl)} \mathrm{groups.} \mathrm{Rats} \mathrm{in} \mathrm{the} \mathrm{normal} \mathrm{CTA} \mathrm{group} \mathrm{showed} \mathrm{a}$ significantly higher aversion index of both STM and LTM compared with animals in the other two groups $\left(n=5-6\right.$; $\left.{ }^{* *} p<0.01\right)$. ormal training groups normalized to $C S$ control group $\left(n=5,{ }^{*} p<0.05\right)$. C, Relative levels of $\mathrm{p}$-TrkB in CeA in the CS control, pY99 antibodies (top) or mouse anti-TrkB antibodies (bottom). The right panel in C depicts the densitometric analyses showing the relative TrkB phosphorylation levels over total TrkB at 1 and $8 \mathrm{~h}$ after conditioning in the weak and normal CTA group normalized to CS control $\left(n=3 ;{ }^{*} p<0.05,{ }^{* *} p<0.01\right)$. D, Schematic representation of the behavior protocol to evaluate the effect of hrBDNF administration in the CeA on CTA memory formation. Vehicle or hrBDNF was microinfused into the CeA immediately after of hrBDNF, but not vehicle, completely rescued the impaired CTA STM and LTM induced by weak training. The values represent means \pm SEM, determined from analysis of 8 rats per group $\left({ }^{* *} p<0.01\right)$.

and reverse the CTA memory deficits induced by protein synthesis inhibition (Moguel-González et al., 2008). Our findings further demonstrate the importance of BDNF signaling in the CeA in CTA memory formation.

In conclusion, using the CTA memory paradigm, we determined the spatial-specific roles of BDNF in CTA memory formation. We provided evidence, for the first time to our knowledge, that dynamic regulation of $\mathrm{BDNF}$ in the $\mathrm{CeA}$, but not $\mathrm{BLA}$, played important roles in CTA acquisition. In addition, activity-dependent secretion and synthesis of BDNF in the CeA were respectively required for CTA acquisition and consolidation through activation of TrkB. Finally, we found that microinfusion of BDNF in the CeA could enhance CTA memory. Our study will help further the understanding of the precise regulation of BDNF in different memory phases depending on its location in the neural circuit. 


\section{References}

Alfonso J, Frick LR, Silberman DM, Palumbo ML, Genaro AM, Frasch AC (2006) Regulation of hippocampal gene expression is conserved in two species subjected to different stressors and antidepressant treatments. Biol Psychiatry 59:244-251.

Alonso M, Vianna MR, Depino AM, Mello e Souza T, Pereira P, Szapiro G, Viola H, Pitossi F, Izquierdo I, Medina JH (2002) BDNF-triggered events in the rat hippocampus are required for both short- and long-term memory formation. Hippocampus 12:551-560.

Bahar A, Samuel A, Hazvi S, Dudai Y (2003) The amygdalar circuit that acquires taste aversion memory differs from the circuit that extinguishes it. Eur J Neurosci 17:1527-1530.

Barde YA, Davies AM, Johnson JE, Lindsay RM, Thoenen H (1987) Brain derived neurotrophic factor. Prog Brain Res 71:185-189.

Bekinschtein P, Cammarota M, Igaz LM, Bevilaqua LR, Izquierdo I, Medina JH (2007) Persistence of long-term memory storage requires a late protein synthesis- and BDNF-dependent phase in the hippocampus. Neuron 53:261-277.

Berman DE, Hazvi S, Rosenblum K, Seger R, Dudai Y (1998) Specific and differential activation of mitogen-activated protein kinase cascades by unfamiliar taste in the insular cortex of the behaving rat. J Neurosci 18:10037-10044.

Berman DE, Hazvi S, Neduva V, Dudai Y (2000) The role of identified neurotransmitter systems in the response of insular cortex to unfamiliar taste: activation of ERK1-2 and formation of a memory trace. J Neurosci 20:7017-7023.

Bermúdez-Rattoni F (2004) Molecular mechanisms of taste-recognition memory. Nat Rev Neurosci 5:209-217.

Bermudez-Rattoni F, McGaugh JL (1991) Insular cortex and amygdala lesions differentially affect acquisition on inhibitory avoidance and conditioned taste aversion. Brain Res 549:165-170.

Berton O, Nestler EJ (2006) New approaches to antidepressant drug discovery: beyond monoamines. Nat Rev Neurosci 7:137-151.

Berton O, McClung CA, Dileone RJ, Krishnan V, Renthal W, Russo SJ, Graham D, Tsankova NM, Bolanos CA, Rios M, Monteggia LM, Self DW, Nestler EJ (2006) Essential role of BDNF in the mesolimbic dopamine pathway in social defeat stress. Science 311:864-868.

Castillo DV, Escobar ML (2011) A role for MAPK and PI-3K signaling pathways in brain-derived neurotrophic factor modification of conditioned taste aversion retention. Behav Brain Res 217:248-252.

Castillo DV, Figueroa-Guzmán Y, Escobar ML (2006) Brain-derived neurotrophic factor enhances conditioned taste aversion retention. Brain Res 1067:250-255.

Chao MV (2003) Neurotrophins and their receptors: a convergence point for many signalling pathways. Nat Rev Neurosci 4:299-309.

Chen ZY, Patel PD, Sant G, Meng CX, Teng KK, Hempstead BL, Lee FS (2004) Variant brain-derived neurotrophic factor (BDNF) (Met66) alters the intracellular trafficking and activity-dependent secretion of wildtype BDNF in neurosecretory cells and cortical neurons. J Neurosci 24:4401-4411.

Chen ZY, Jing D, Bath KG, Ieraci A, Khan T, Siao CJ, Herrera DG, Toth M, Yang C, McEwen BS, Hempstead BL, Lee FS (2006) Genetic variant BDNF (Val66Met) polymorphism alters anxiety-related behavior. Science 314:140-143.

Chhatwal JP, Stanek-Rattiner L, Davis M, Ressler KJ (2006) Amygdala BDNF signaling is required for consolidation but not encoding of extinction. Nat Neurosci 9:870-872.

Desmedt A, Hazvi S, Dudai Y (2003) Differential pattern of cAMP response element-binding protein activation in the rat brain after conditioned aversion as a function of the associative process engaged: taste versus context association. J Neurosci 23:6102-6110.

Egan MF, Kojima M, Callicott JH, Goldberg TE, Kolachana BS, Bertolino A, Zaitsev E, Gold B, Goldman D, Dean M, Lu B, Weinberger DR (2003) The BDNF val66met polymorphism affects activity-dependent secretion of BDNF and human memory and hippocampal function. Cell 112:257-269

Eisch AJ, Bolaños CA, de Wit J, Simonak RD, Pudiak CM, Barrot M, Verhaagen J, Nestler EJ (2003) Brain-derived neurotrophic factor in the ventral midbrain-nucleus accumbens pathway: a role in depression. Biol Psychiatry 54:994-1005.

Escobar ML, Figueroa-Guzmán Y, Gómez-Palacio-Schjetnan A (2003) In vivo insular cortex LTP induced by brain-derived neurotrophic factor. Brain Res 991:274-279.

Finkbeiner S, Tavazoie SF, Maloratsky A, Jacobs KM, Harris KM, Greenberg ME (1997) CREB: a major mediator of neuronal neurotrophin responses. Neuron 19:1031-1047.

Gallo M, Cándido A (1995) Dorsal hippocampal lesions impair blocking but not latent inhibition of taste aversion learning in rats. Behav Neurosci 109:413-425.

Gallo M, Bielavska E, Roldán G, Bures J (1998) Tetrodotoxin inactivation of the gustatory cortex disrupts the effect of the N-methyl-D-aspartate antagonist ketamine on latent inhibition of conditioned taste aversion in rats. Neurosci Lett 240:61-64.

Gutiérrez R, Rodriguez-Ortiz CJ, De La Cruz V, Núñez-Jaramillo L, Bermudez-Rattoni F (2003) Cholinergic dependence of taste memory formation: evidence of two distinct processes. Neurobiol Learn Mem $80: 323-331$.

Hall J, Thomas KL, Everitt BJ (2000) Rapid and selective induction of BDNF expression in the hippocampus during contextual learning. Nat Neurosci 3:533-535.

Harada C, Harada T, Quah HM, Namekata K, Yoshida K, Ohno S, Tanaka K, Parada LF (2005) Role of neurotrophin-4/5 in neural cell death during retinal development and ischemic retinal injury in vivo. Invest Ophthalmol Vis Sci 46:669-673.

Huang EJ, Reichardt LF (2001) Neurotrophins: roles in neuronal development and function. Annu Rev Neurosci 24:677-736.

Jarrard LE (1989) On the use of ibotenic acid to lesion selectively different components of the hippocampal formation. J Neurosci Methods 29:251-259.

Jarrard LE (2002) Use of excitotoxins to lesion the hippocampus: update. Hippocampus 12:405-414.

Jiang B, Akaneya Y, Ohshima M, Ichisaka S, Hata Y, Tsumoto T (2001) Brain-derived neurotrophic factor induces long-lasting potentiation of synaptic transmission in visual cortex in vivo in young rats, but not in the adult. Eur J Neurosci 14:1219-1228.

Kaplan DR, Miller FD (2000) Neurotrophin signal transduction in the nervous system. Curr Opin Neurobiol 10:381-391.

Kesslak JP, So V, Choi J, Cotman CW, Gomez-Pinilla F (1998) Learning upregulates brain-derived neurotrophic factor messenger ribonucleic acid: a mechanism to facilitate encoding and circuit maintenance? Behav Neurosci 112:1012-1019.

Kim KS, Han PL (2006) Optimization of chronic stress paradigms using anxiety- and depression-like behavioral parameters. J Neurosci Res 83:497-507.

Koponen E, Võikar V, Riekki R, Saarelainen T, Rauramaa T, Rauvala H, Taira T, Castrén E (2004) Transgenic mice overexpressing the full-length neurotrophin receptor trkB exhibit increased activation of the trkBPLCgamma pathway, reduced anxiety, and facilitated learning. Mol Cell Neurosci 26:166-181.

Krystal JH, Duman R (2004) What's missing in posttraumatic stress disorder research? Studies of human postmortem tissue. Psychiatry 67:398-403.

Lamprecht R, Hazvi S, Dudai Y (1997) cAMP response element-binding protein in the amygdala is required for long- but not short-term conditioned taste aversion memory. J Neurosci 17:8443-8450.

Laurent V, Westbrook RF (2009) Infusion of the NMDA receptor antagonist, DL-APV, into the basolateral amygdala disrupts learning to fear a novel and a familiar context as well as relearning to fear an extinguished context. Learn Mem 16:96-105.

Lee H, Kim JJ (1998) Amygdalar NMDA receptors are critical for new fear learning in previously fear-conditioned rats. J Neurosci 18:8444-8454.

Lee JL, Everitt BJ, Thomas KL (2004) Independent cellular processes for hippocampal memory consolidation and reconsolidation. Science 304:839-843.

Leibrock J, Lottspeich F, Hohn A, Hofer M, Hengerer B, Masiakowski P, Thoenen H, Barde YA (1989) Molecular cloning and expression of brain-derived neurotrophic factor. Nature 341:149-152.

Linnarsson S, Björklund A, Ernfors P (1997) Learning deficit in BDNF mutant mice. Eur J Neurosci 9:2581-2587.

Mickley GA, Kenmuir CL, Yocom AM, Wellman JA, Biada JM (2005) A role for prefrontal cortex in the extinction of a conditioned taste aversion. Brain Res 1051:176-182.

Minichiello L, Korte M, Wolfer D, Kühn R, Unsicker K, Cestari V, Rossi- 
Arnaud C, Lipp HP, Bonhoeffer T, Klein R (1999) Essential role for TrkB receptors in hippocampus-mediated learning. Neuron 24:401-414.

Moguel-González M, Gómez-Palacio-Schjetnan A, Escobar ML (2008) BDNF reverses the CTA memory deficits produced by inhibition of protein synthesis. Neurobiol Learn Mem 90:584-587.

Mu JS, Li WP, Yao ZB, Zhou XF (1999) Deprivation of endogenous brainderived neurotrophic factor results in impairment of spatial learning and memory in adult rats. Brain Res 835:259-265.

Naor C, Dudai Y (1996) Transient impairment of cholinergic function in the rat insular cortex disrupts the encoding of taste in conditioned taste aversion. Behav Brain Res 79:61-67.

Pandey SC, Zhang H, Roy A, Misra K (2006) Central and medial amygdaloid brain-derived neurotrophic factor signaling plays a critical role in alcohol-drinking and anxiety-like behaviors. J Neurosci 26:8320-8331.

Paxinos G, Watson C (1996) The rat brain in stereotaxic coordinates, Ed 3. New York: Academic

Rattiner LM, Davis M, French CT, Ressler KJ (2004) Brain-derived neurotrophic factor and tyrosine kinase receptor B involvement in amygdaladependent fear conditioning. J Neurosci 24:4796-4806.

Rosenblum K, Meiri N, Dudai Y (1993) Taste memory: the role of protein synthesis in gustatory cortex. Behav Neural Biol 59:49-56.

Rosenblum K, Berman DE, Hazvi S, Lamprecht R, Dudai Y (1997) NMDA receptor and the tyrosine phosphorylation of its $2 \mathrm{~B}$ subunit in taste learning in the rat insular cortex. J Neurosci 17:5129-5135.

Tongiorgi E, Righi M, Cattaneo A (1998) A non-radioactive in situ hybridization method that does not require RNAse-free conditions. J Neurosci Methods 85:129-139.

Tongiorgi E, Armellin M, Giulianini PG, Bregola G, Zucchini S, Paradiso B, Steward O, Cattaneo A, Simonato M (2004) Brain-derived neurotrophic factor mRNA and protein are targeted to discrete dendritic laminas by events that trigger epileptogenesis. J Neurosci 24:6842-6852.

Tucci S, Rada P, Hernandez L (1998) Role of glutamate in the amygdala and lateral hypothalamus in conditioned taste aversion. Brain Res 813:44-49.

Welzl H, D’Adamo P, Lipp HP (2001) Conditioned taste aversion as a learning and memory paradigm. Behav Brain Res 125:205-213.

Yamamoto T, Fujimoto Y (1991) Brain mechanisms of taste aversion learning in the rat. Brain Res Bull 27:403-406.

Yasoshima Y, Morimoto T, Yamamoto T (2000) Different disruptive effects on the acquisition and expression of conditioned taste aversion by blockades of amygdalar ionotropic and metabotropic glutamatergic receptor subtypes in rats. Brain Res 869:15-24.

Yu H, Wang Y, Pattwell S, Jing D, Liu T, Zhang Y, Bath KG, Lee FS, Chen ZY (2009) Variant BDNF Val66Met polymorphism affects extinction of conditioned aversive memory. J Neurosci 29:4056-4064. 